\title{
Investigating Combined Drug and Plasma Apheresis Therapy of HIV Infection by Double Compartment Cellular Automata Simulation
}

\author{
Sompop Moonchai and Yongwimon Lenbury
}

\begin{abstract}
It has become widely acknowledged that potent combination drug therapy of patients infected with Human Immunodeficiency Virus can significantly prolong life, but exerts detrimental effect on a patient's quality of life. Lymph nodes and lymphatic tissue are busy sites of immunological activity. Germs are brought there by the cells of the immune system to be broken down and analyzed. However, clinics commonly used blood tests for viral load therein to assess the effect of drug therapy. We are therefore of the opinion that most cellular automata models in the past that only considered viral proliferation in the lymph node cannot give a sufficiently accurate picture of the dynamics of HIV infection, especially when the impact of treatments that combine both drugs and plasma apheresis are in question. We thus present a two-compartment cellular automata (CA) model, which simulates the dynamics of HIV infection in both the lymph node and blood compartments when drugs and plasma apheresis are applied simultaneously. It is found that the combined usage of these two types of therapy yields more favorable outcome than the sole use of plasma apheresis.
\end{abstract}

Index Terms-Cellular automata, HIV, HAART, plasma apheresis.

\section{INTRODUCTION}

Ever since the HIV epidemic first became apparent in the early 1980s, scientists have studied lymph node biopsies and discovered evidence of a large collection of Human Immunodeficiency Virus (HIV) there in addition to active infection of cells in that compartment [1]. However, later research works have become concentrated on blood and cells of the immune system extracted from blood because this was easier to obtain and simpler to analyze. Moreover, availability of assays to assess viral load and the life-extending effect of treatment available for blood samples makes assaying lymph nodes and lymphatic tissue less necessary.

CA models were first used by Zorzenon dos Santos and Coutinho [2] to model the evolution of HIV infection. It was originally proposed that the lymphatic tissue is the primary

Manuscript received November 30, 2014; revised March 3, 2015. This work was supported in part by the Mahidol University under Grant C02/2557, and the Centre of Excellence in Mathematics, PERDO, CHE, Thailand.

Sompop Moonchai is with the Department of Mathematics, Chiang Mai University, Chiang Mai, Thailand (e-mail: tumath@gmail.com).

Yongwimon Lenbury is with the Department of Mathematics, Faculty of Science, Mahidol University, Rama 6 Rd., Bangkok 10400, Thailand, and the Centre of Excellence in Mathematics, PERDO, CHE, Thailand (e-mail: scylb@yahoo.com). target of HIV infection and a major reservoir of HIV in human [3], and the lymph node has a mesh structure that may be approximated by a rough surface [4]. On such consideration, it is thus reasonable to model the interaction among the immune system cells in the lymphatic tissues using a square lattice. Many articles [1], [5]-[7] have developed CA models to explain the dynamics of HIV infection. Most of these CA models only considered the dynamics in the lymph node. However, as mentioned above, most clinical indications of progression are based on blood data, because these data are most easily obtained and simpler to investigate. Moreover, viral population circulates between the lymph node and plasma compartments, viral load in the two compartments are important for the description of the dynamics of HIV infection.

In the work of Moonchai, Lenbury and Triampo [8], then that of Moonchai and Lenbury [9], and the more recent work of Moonchai and Lenbury [10], the CA rules based on Zorzenon dos Santos and Coutinho CA model [1] were modified to illustrate the use of double latticed CA simulation to investigate the dynamics of HIV infection in both the lymph node and blood compartments whereas the viral load in the two compartments is continuously updated throughout the simulation. In the work of Moonchai and Lenbury [9], the model incorporated the use of potent combination drug therapy (commonly called ART or HAART) to investigate the treatment outcome based on different drug's efficacy and effectiveness. In the more recent work of Moonchai and Lenbury [10], the CA model proposed by Moonchai et al. [8] was then modified to investigate the effectiveness of treatment by plasma apheresis.

Treatment by plasma aphaeresis has been used effectively on patients afflicted with hepatitis C infection [11]-[14], and cancer [15]. In plasma aphaeresis, the virus particles in the larger components of the plasma are removed from a patient, after which the small molecular components of plasma and cellular components of the blood are returned to the patient. Several research reports have indicated that plasma apheresis may offer a good alternative for the treatment of AIDS patients [16]-[19]. Several researchers [19]-[22] have reported that plasma apheresis in combination with drug prescription can be efficacious treatment of HIV patients.

The result of our simulation study [10] indicated that it may be possible that, under certain conditions, during the 4 week breaks from plasma apheresis treatment the blood viral load may rebound to levels higher than the no treatment levels, which may lead to serious complications. There is the risk that the treated patient could be more vulnerable to 
opportunistic infection during these times than an untreated patient. This possibility depends on when the treatment is started during the course of infection and the treatment frequency, so that the benefit of treating patients with this therapeutic option is not conclusive.

This then leaves us with the hypothesis that perhaps the combined usage of both HARRT and plasma apheresis could become a viable treatment option that could have the desirable effect of controlling the infection at a manageable level. In this paper, we utilize a CA model to investigate how effective such combined treatment could be, by modifying the $\mathrm{CA}$ rules in our earlier works [8]-[10]. Experiments with different killing efficacy of the drugs and different clearance rate of the apheresis treatment illustrate how it may be more favorable, when the appropriate treatment conditions are met, over the use of plasma apheresis alone.

\section{MODELING HIV DYNAMICS}

\section{A. Cellular Automata Model}

Our Cellular Automata model of HIV infection is based on double two-dimensional $L \times L$ square lattices, in which each site represents a cell. The Moore neighborhood, consisting of the surrounding 8 adjacent cells and the central cell, is used to define the rules to update the cells. Each cell in the lattice is assigned one of the five states that describe the possible states in which those cells may be found: non-activated or non-proliferating cells $(N)$, healthy cells $(H)$, infected A1 cells $\left(A_{1}\right)$, infected A2 cells $\left(A_{2}\right)$, or dead cells $(D)$. At each time step (corresponding to one week), the state of the cell is updated in parallel according to the update rules. The meaning of each state is defined as follows: Non-activated cells are cells which may become an active healthy cell. Healthy cells are CD4+ T-cells which are the main target of HIV. Infected A1 cells are infected cells in the earlier stages which are free to spread the infection. Infected A2 cells are infected cells in the final stage before dying due to the action of the immune system. Dead cells are infected cells killed by the immune response [8].

In this work, we modify a CA model of HIV infection in two coupled compartments; the lymph node compartment and the peripheral blood compartment, which was proposed by Moonchai and Lenbury [9]. For each compartment, we use the periodic boundary condition and the simulation steps start with the initial numbers of cells in different states distributed randomly; namely, $N_{0}$ non-activated cells, $H_{0}$ healthy cells, and $A_{1,0}$ infected A1 cell, $A_{1,0}=P_{\mathrm{HIV}} H_{0}$, with a small probability $P_{\mathrm{HIV}}$. In addition, the initial viral load $V_{0}$ is used in the viral load simulation.

TABLE I: UPDAING RULES IN CA MODEL

\begin{tabular}{|c|c|}
\hline Number & Description \\
\hline $\begin{array}{l}\text { Rule } 1 \text { (modified } \\
\text { from [9]) }\end{array}$ & $\begin{array}{l}\text { Updates of non-proliferating cells } N \text {. } \\
\text { a) If a non-proliferating cell has only non-proliferating cells as its neighbors, it may become an active healthy cell at the } \\
\text { probability } P_{\text {op }} \text {, accounting for opportunistic infection, or it remains the same at the probability } 1-P_{\text {op. }} \text {. } \\
\text { b) If it has a neighbor which is A1 or A2 infected, it becomes an active healthy cell, by which the body tries to fight the infection. } \\
\text { c) After steps (a) and (b) a non-proliferating cell can be replaced by an infected A1 cell with the probability } P_{\text {repl }} \text {. Otherwise, it } \\
\text { remains a non-proliferating cell at the probability } 1-P_{\text {repl }} \text {. }\end{array}$ \\
\hline $\begin{array}{l}\text { Rule } 2 \text { (modified } \\
\text { from [9]) }\end{array}$ & $\begin{array}{l}\text { Update of healthy cells } \boldsymbol{H} \\
\text { a) An active healthy cell gets infected by coming in contact with a virus at the probability } P_{v}^{*}=P_{v}\left(1-e^{-a V_{t}}\right) \text {, where } V_{t} \\
\text { represents the viral load in that compartment. } \\
\text { b) If it has at least one infected A1 - neighbor, it becomes an infected A1 cell at the probability } P_{1}^{*}=r_{1}\left(1-P_{v}^{*}\right) \text {. } \\
\text { c) If it has no infected A1 neighbor, but has at least } R(2<R<8) \text { infected A2 neighbors, it becomes an infected A1 cell at the } \\
\text { probability } P_{2}^{*}=r_{2}\left(1-r_{1}\right)\left(1-P_{v}^{*}\right) \text {. } \\
\text { d) Otherwise, it remains a healthy cell at the probability } 1-P_{1}^{*}-P_{2}^{*}-P_{v}^{*} \text {, where } 0<P_{1}^{*}+P_{2}^{*}+P_{v}^{*}<1 . \\
\text { e) After step (d), an infected A1 cell remains an infected A1 cell at the probability } 1-P_{d}(t) \text {. } \\
\text { Otherwise, it becomes a healthy cell in the next time step at the probability } P_{d}(t) \text { being the drug efficacy probability due to the } \\
\text { reverse transcriptase inhibitor at time } t \text { after an initial time of treatment } T_{d} \text { given as follows: } \\
\qquad P_{d}(t)=\left\{\begin{array}{l}0, \quad t<T_{d} \\
\mu\left(1+\frac{I_{t}+I_{d}}{H_{0}}\right)^{-\eta} \sqrt{\frac{I_{d}}{H_{0}}\left(t-T_{d}\right)}, t \geq T_{d}\end{array}\right. \\
\text { where } I_{t}=A_{1 t}+A_{2 t} \text { and } I_{d}=A_{1 d}+A_{2 d} \text { are the numbers of infected A1 and infected A2 cells at time } t \text { and the initiation of } \\
\text { treatment } T_{d} \text {, respectively. }\end{array}$ \\
\hline $\begin{array}{c}\text { Rule } 3 \\
{[2]}\end{array}$ & $\begin{array}{l}\text { Update of infected A1 cells } \\
\text { An infected A1 cell becomes an infected A2 cell after } \tau \text { time steps. Thus, different infected A1 cells become infected A2 cells at } \\
\text { different times with a delay of } \tau \text {. }\end{array}$ \\
\hline $\begin{array}{c}\text { Rule } 4 \\
{[2]}\end{array}$ & $\begin{array}{l}\text { Update of infected A2 cells } \\
\text { Infected A2 cells become dead cells, corresponding to the depletion of infected cells by the immune response. }\end{array}$ \\
\hline $\begin{array}{l}\text { Rule } 5 \\
\text { (modified from } \\
[9])\end{array}$ & $\begin{array}{l}\text { Updates of dead cells } \boldsymbol{D} \\
\quad \text { A dead cell can be replaced by an inactivated cell with the probability } P_{\text {nona }} \text {.Otherwise, it remains a dead cell at the probability } \\
1-P_{\text {nona }} \text {. }\end{array}$ \\
\hline
\end{tabular}




\section{B. Updating Rules}

Here, we investigate the effect of various types of drugs and plasma apheresis treatments on the progression of AIDS. Our CA model simulates HIV infection using the updating rules, modified from the work of Moonchai and Lenbury [9] listed in Table I. The drug action due to the reverse transcriptase inhibitor is incorporated in Rule 2 with the use of potency probability $P_{d}$. The update rules for non-proliferating and dead cells have also been changed for more realistic effect. The rest of the rules are as utilized by Zorzenon dos Santos and Coutinho [2], but listed here for completeness. At each time step, all cells on both lattices of the two coupled compartments; the lymph node compartment and the peripheral blood compartment, are updated according to these rules.

TABLE II: VALUES OF THE PARAMETERS IN CA MODEL IN THE LYMPH NODE AND THE BLOOD COMPARTMENTS

\begin{tabular}{|c|c|c|c|}
\hline Symbol & Definition & $\begin{array}{r}\text { Lymph node } \\
\text { [reference] }\end{array}$ & $\begin{array}{c}\text { Blood } \\
\text { [reference] }\end{array}$ \\
\hline$L$ & Lattice size & 500 & 500 \\
\hline$N_{0}$ & $\begin{array}{l}\text { Number of non-activated or } \\
\text { non-proliferating cells at } t=0\end{array}$ & 250,000 & 250,000 \\
\hline$H_{0}$ & $\begin{array}{l}\text { Number of healthy active cells at } \\
t=0\end{array}$ & 125,000 & 125,000 \\
\hline$P_{\text {HIV }}$ & Probability of initial infected cells & $\begin{array}{c}0.05 \\
{[2]}\end{array}$ & $\begin{array}{c}0.05 \\
{[2]}\end{array}$ \\
\hline$P_{\mathrm{op}}$ & $\begin{array}{l}\text { Probability for a non-proliferating } \\
\text { cell to be replaced with an active } \\
\text { healthy cell }\end{array}$ & $\begin{array}{c}0.001 \\
\text { (estimated) }\end{array}$ & $\begin{array}{c}0.001 \\
\text { (estimated) }\end{array}$ \\
\hline$P_{v}$ & $\begin{array}{l}\text { Constant in probability for a } \\
\text { healthy cell to come in contact } \\
\text { with a virus }\end{array}$ & $\begin{array}{c}0.0002 \\
\text { (estimated) }\end{array}$ & $\begin{array}{c}0.0001 \\
\text { (estimated) }\end{array}$ \\
\hline$a$ & Constant in probability $P_{v}^{*}$ & $1 \times 10^{-16}$ & $1 \times 10^{-7}$ \\
\hline$r_{1}$ & Constant in probability $P_{1}^{*}$ & $\begin{array}{c}0.997 \\
\text { (estimated) }\end{array}$ & $\begin{array}{c}0.997 \\
\text { (estimated) }\end{array}$ \\
\hline$r_{2}$ & Constant in probability $P_{2}^{*}$ & $\begin{array}{c}0.997 \\
\text { (estimated) }\end{array}$ & $\begin{array}{c}0.997 \\
\text { (estimate) } \\
\end{array}$ \\
\hline$\mu$ & Constant in probability $P_{d}$ & $\begin{array}{c}0.9 \\
\text { (estimated) } \\
\end{array}$ & $\begin{array}{c}0.9 \\
\text { (estimated) }\end{array}$ \\
\hline$\eta$ & Constant in probability $P_{d}$ & $\begin{array}{c}0.05 \\
\text { (estimated) } \\
\end{array}$ & $\begin{array}{c}0.05 \\
\text { (estimated) } \\
\end{array}$ \\
\hline$\tau$ & $\begin{array}{l}\text { Time delay for an infected A1 cell } \\
\text { to become an infected A2 cell }\end{array}$ & \begin{tabular}{r|r}
4 \\
{$[2]$}
\end{tabular} & $\begin{array}{c}4 \\
{[2]}\end{array}$ \\
\hline$P_{\text {repl }}$ & $\begin{array}{l}\text { Probability that non-prolifera- ting } \\
\text { cell is replaced with infected A1 } \\
\text { cell }\end{array}$ & $1 \times 10^{-16}$ & $1 \times 10^{-16}$ \\
\hline$P_{\text {nona }}$ & $\begin{array}{l}\text { Probability that death cell is } \\
\text { replaced by non-activated cells }\end{array}$ & $\begin{array}{c}0.9 \\
\text { (estimated) }\end{array}$ & $\begin{array}{c}0.9 \\
\text { (estimated) }\end{array}$ \\
\hline$R$ & $\begin{array}{l}\text { Number of infected A2 cells in a } \\
\text { cell neighborhood to induce a } \\
\text { healthy cell to become an infected } \\
\text { A1 cell }\end{array}$ & $\begin{array}{c}4 \\
{[2]}\end{array}$ & $\begin{array}{c}4 \\
{[2]}\end{array}$ \\
\hline
\end{tabular}

The definitions and values of all the parameters and probabilities, some of which were used in the works of Moonchai et al. [8], Moonchai and Lenbury [9], and a more recent work by Moonchai and Lenbury [10] whereas some are new estimates, utilized in these rules are given in Table II.

\section{Viral Load Model}

Concurrently at each time step, the viral load in the lymph node compartment $V_{t}^{L}$ and the peripheral blood compartment $V_{t}^{B}$ are updated by the following rules, as done in [8]-[10].

- In the lymph node compartment

$$
V_{t+1}^{L}-V_{t}^{L}=p S_{L} I_{t}^{L}+\left(\alpha \cdot V_{t}^{B}-\tilde{V}_{L}\right)-c_{L H} H_{t}^{L} V_{t}^{L}-c V_{t}^{L}
$$

where $I_{t}^{L}=A_{1, t}^{L}+A_{2, t}^{L}$ and $\tilde{V}_{L}=e\left(V_{t}^{L}+\alpha \cdot V_{t}^{B}\right)$.

- In the blood compartment

$$
V_{t+1}^{B}-V_{t}^{B}=p S_{B} I_{t}^{B}+\left(\tilde{V}_{B}-V_{t}^{B}\right)-c_{B H} H_{t}^{B} V_{t}^{B}-c V_{t}^{B}-\varepsilon V_{t}^{B}
$$

where $I_{t}^{B}=A_{1, t}^{B}+A_{2, t}^{B}$ and $\tilde{V}_{B}=e\left(\beta \cdot V_{t}^{L}+V_{t}^{B}\right)$.

Here, $A_{1 t}^{L}$ and $A_{2 t}^{L}$ are the numbers of infected A1 and infected A2 cells in the lymph node at time $t$, respectively, $A_{1 t}^{B}$ and $A_{2 t}^{B}$ are the numbers of infected A1 and infected A2 cells in the blood compartment, $H_{t}^{L}$ and $H_{t}^{B}$ are the numbers of healthy cells in the respective compartments at time $t, p$ is the average viral production rate per infected cell, $e$ represents the circulation ratio of virus between the two compartments, $c$ is the death rate of free virus, and $\varepsilon$ is the free virus clearance rate constant due to plasma apheresis treatment.

The values of the parameters appearing in these equations for viral load calculation used in our simulations are given in Table III, some of which were used in in our earlier works [8]-[10] whereas some are new estimates.

\begin{tabular}{|c|c|c|}
\hline Symbol & Definition & $\begin{array}{c}\text { Value } \\
\text { [reference] }\end{array}$ \\
\hline$V_{0}^{B}$ & Plasma virus concentration at $t=0$ & $\begin{array}{l}10[23] \\
\text { (can vary) }\end{array}$ \\
\hline$V_{0}^{L}$ & $\begin{array}{l}\text { Virus concentration in the lymph node at } \\
t=0\end{array}$ & 0 \\
\hline$p$ & $\begin{array}{l}\text { Average virion production rate per infected } \\
\text { cell }\end{array}$ & $480[24]$ \\
\hline$S_{L}$ & Scaling factor in the lymph node & $2 \times 10^{11} / H_{0}$ \\
\hline$S_{B}$ & Scaling factor in the blood & $1000 / H_{0}$ \\
\hline$c_{L H}$ & $\begin{array}{l}\text { Clearance rate of free virus in the lymph } \\
\text { node }\end{array}$ & $\begin{array}{l}4 \times 10^{-6} \\
\text { (estimated) }\end{array}$ \\
\hline$c_{B H}$ & Clearance rate of free virus in the blood & $\begin{array}{l}4 \times 10^{-6} \\
\text { (estimated) }\end{array}$ \\
\hline$c$ & Death rate of free virus & $0.3[24]$ \\
\hline$e$ & $\begin{array}{l}\text { Circulation fraction of virus between lymph } \\
\text { node and blood }\end{array}$ & $0.02[25]$ \\
\hline$\beta$ & Scaling factor: lymph node $\rightarrow$ blood & $\begin{array}{l}4 \times 10^{-9} \\
\text { (estimated) }\end{array}$ \\
\hline$\alpha$ & Scaling factor: lymph node $\leftarrow$ blood & $\begin{array}{c}2.5 \times 10^{8} \\
\text { (estimated) }\end{array}$ \\
\hline$\varepsilon$ & $\begin{array}{l}\text { Clearance rate of free virus due to plasma } \\
\text { apheresis }\end{array}$ & $0.5-0.7$ \\
\hline
\end{tabular}

TABLE III: THE PARAMETERS IN VIRAL LOAD MODELS

\section{SimUlation RESUltS AND DisCUSSION}

Here, the results of CA model simulations are averaged over 50 runs using the parametric values in Tables II and III. In the simulation, the drug and plasma apheresis treatment are modeled by varying the value of the apheresis clearance rate $\varepsilon$.

The drug and plasma apheresis treatments start at two initial treatment times: week 250 and week 300 . The plasma 
apheresis therapy is performed at a frequency of once every 5 weeks and the treatments are provided for 150 weeks.
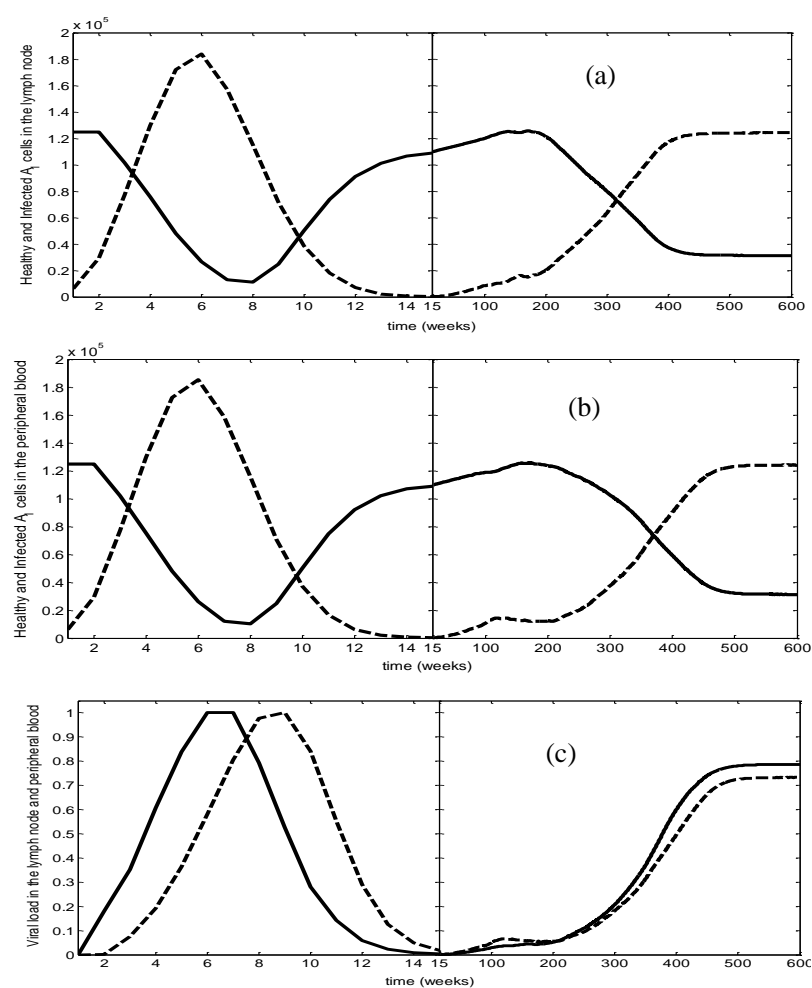

Fig. 1. Simulated time courses of (a) the numbers of healthy (solid line) and infected A1 cells (dashed line) in the lymph node, (b) the numbers of healthy (solid line) and infected A1 cells (dashed line) in the peripheral blood, (c) viral load in the lymph node (solid line) and (d) viral load in the peripheral blood (dashed line).

Fig. 1 shows the evolution of healthy cells, infected A1 cells and viral loads in the lymph node and peripheral blood compartments under no treatment. The graphs correctly depict three phases of the HIV infection progression, the acute phase, the chronic phase, and the development to full blown AIDS. The time courses seen here resemble closely those reported by other researchers, for example in [27].

Fig. 2 shows the simulated time courses of healthy cells, infected A1 and viral loads in the lymph node and peripheral blood compartments under drug therapy only, started at weeks 250 and 350 for $\mu=0.9$. We observe here that the drug is more effective if treatment starts earlier on in the progression of the infection. This necessitates that the symptoms need to be detected as early as possible. Late initiation of drug therapy may reduce the viral load to the same level achieved by an earlier initiation, as seen in the sharp drops in the viral loads in Fig. 2(e) and (f) but eventually, the viral load rises to a higher level and remains significantly higher than that resulting from the treatment initiated 100 weeks earlier.

Fig. 3 shows the effects of the combined drug and plasma apheresis treatment for a duration of 150 weeks with different values of the clearance rate $\varepsilon$ on healthy cells infected A1 cells, and viral load in the lymph node and peripheral blood compartments. The simulated time courses exhibit an increase in healthy cells in comparison to no treatment situation, and a reduction of the infected A1 cells and viral load of the lymph node and blood compartments during the treatments. The effects of plasma apheresis are differentiable from the drug only case in the time courses of the viral load but not in the numbers of healthy cells or A1 cells. This is not surprising considering that the process of apheresis affects to remove the virus from the plasma compartment. Referring the readers to our earlier work by Moonchai and Lenbury [9], we recall that if plasma apheresis was applied alone without any drug prescriptions, every drop in the viral load during treatment is always followed by a sharp rise during the respite from treatment, which peaks at a level even higher than the no treatment case. During these periods, immunological responses are consequently weaker, leaving the body vulnerable to opportunistic infection. Thus, there was a doubt as to whether plasma apheresis could be in fact beneficial, or there is a risk associated to that method of therapy.

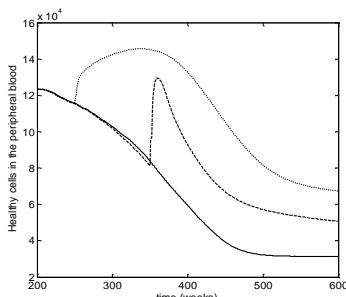

(a)

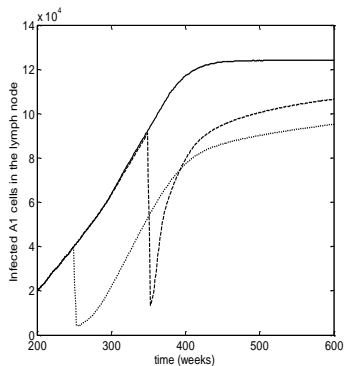

(c)

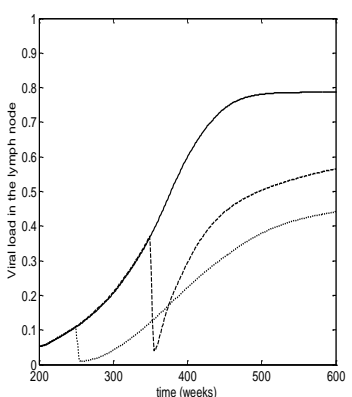

(e)

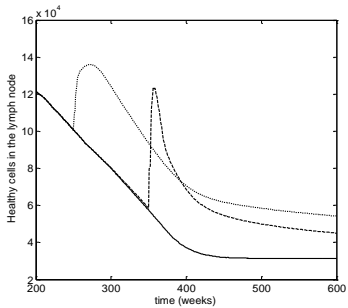

(b)

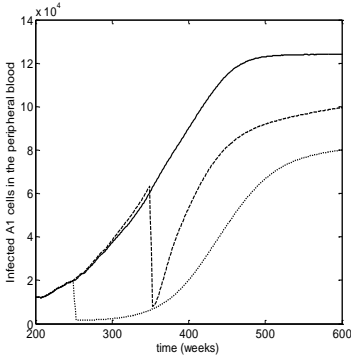

(d)

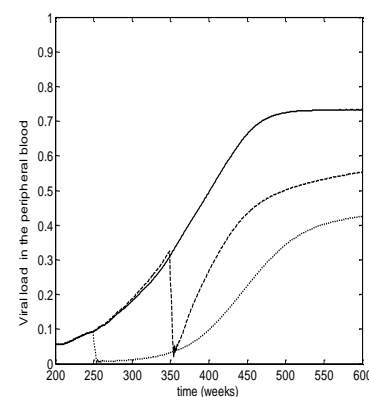

(f)
Fig. 2. Simulated time courses of the healthy cells, infected A1 cells, and viral load concentrations in the lymph node and blood compartments under the drug treatment started at week 250 (dotted line) and week 350 (dashed line) for $\mu=0.9$. (a), (b) The numbers of healthy cells in the lymph node and blood compartments, respectively. (c), (d) The numbers of infected A1 cells in the lymph node and blood compartments, respectively. (e), (f) Viral load in the lymph node and in the peripheral blood compartments, respectively.

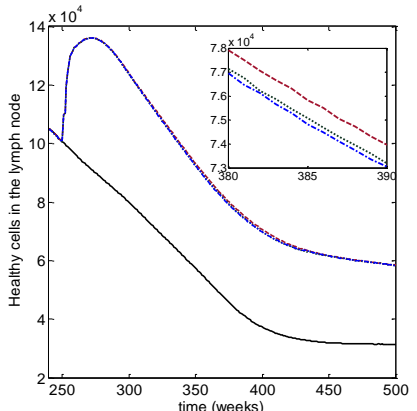

(a)

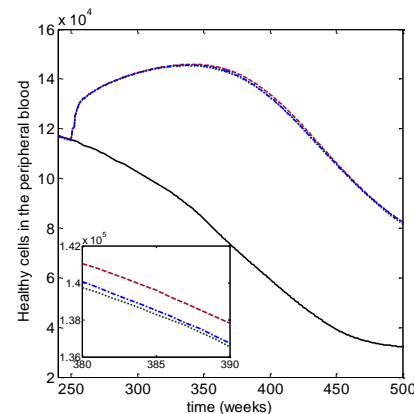

(b) 


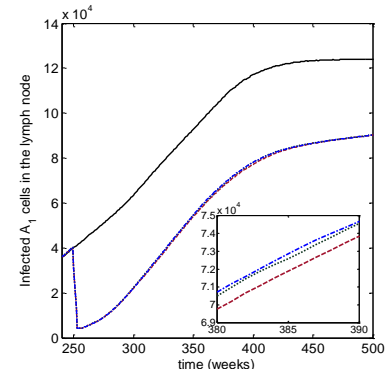

(c)

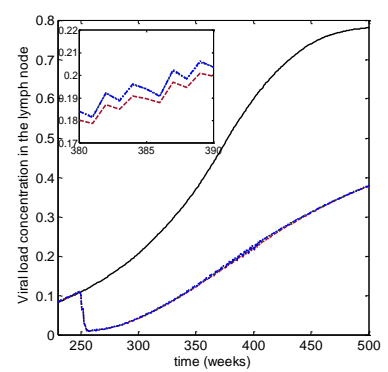

(e)

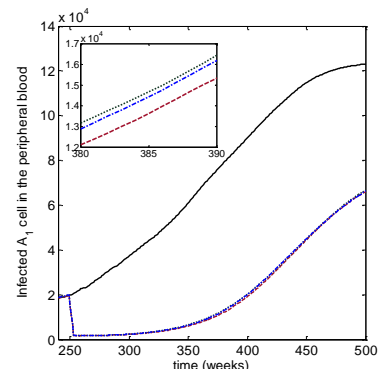

(d)

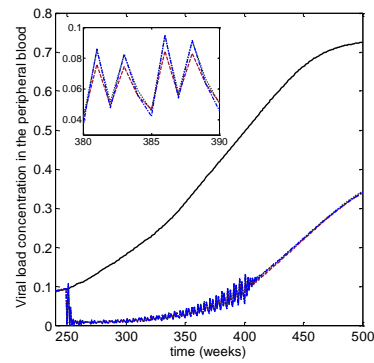

(f)
Fig. 3. Simulated time courses of healthy cells, infected A1 cells, and viral load concentrations in the lymph node and blood compartments under the combined drug and plasma apheresis treatment for a duration of 150 weeks started at week 250 for $\varepsilon=0.5$ (red line), 0.6 (black dotted line) and 0.7 (blue dashed-dot line), compared to the no-treatment situation (black solid line). (a), (b) The numbers of healthy cells in the lymph node and blood compartments, respectively. (c), (d) The numbers of infected A1 cells in the lymph node and blood compartments, respectively. (e), (f) Viral load in the lymph node and in the blood compartments, respectively.

We also note that the swings in the viral load in the blood are more pronounced, the peaks being higher and the lowest points being lower, for larger clearance rates $\varepsilon$. This is due to the fact that a drastic drop in viral load in the blood triggers the transfer of virus particles from the lymph node compartment into the peripheral blood compartment to compensate for the reduced load. The lower the level reaches, the more would be transported in compensation leading to the more drastic overshooting effect. This suggests that care must be taken when a higher clearance rate is used which may not lead to a better outcome entirely. A lower clearance rate may be found to be a relatively more satisfactory prescribed therapy overall. Considering Fig. 3, we observe that if drug prescription is applied in combination with plasma apheresis started at week 250, the drug increases the numbers of healthy cells and reduces the viral load whereas plasma apheresis results in a further viral load reduction. This benefits the patient in creating a better quality of life immediately after the treatment, whereas the peaks of viral load during treatment respites remain below the no treatment case.

Fig. 4 shows the simulated time courses in the case where the treatments start at week 350. Comparing with Fig. 3, the application of apheresis appears to be more effective than if the treatment starts earlier, the viral load dropping lower below the drug only case. This is probably because the viral clearance depends on the viral load at the time. Since the viral load at the start of the treatment at 350 weeks is higher than that at 250 weeks, the virus seems to be removed at a larger quantity. However, if we consider Fig. 5, we see that in fact starting the combined treatment earlier yields a better overall effect. The viral load becomes noticeably lower than that in the treatment started later.

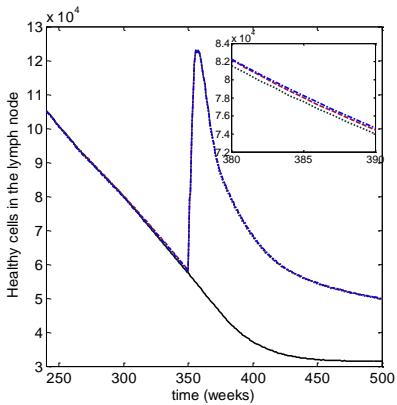

(a)

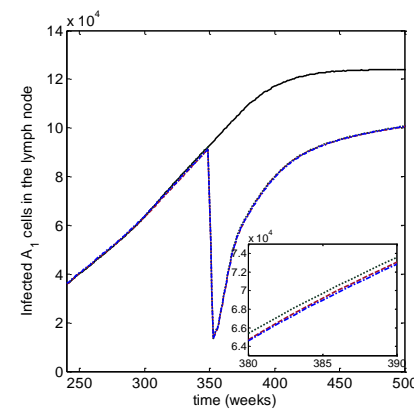

(c)

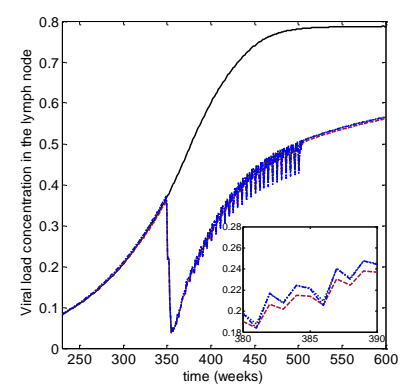

(e)

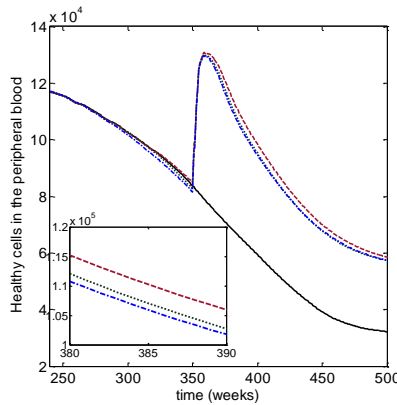

(b)

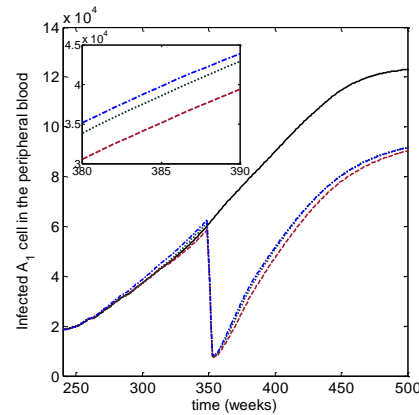

(d)

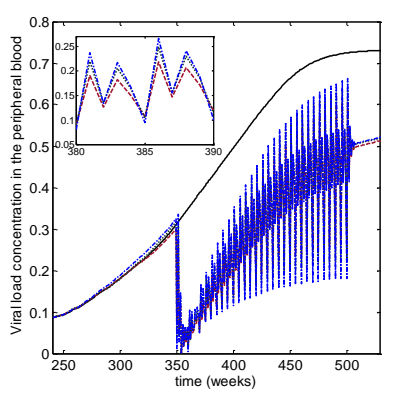

(f)
Fig. 4. Simulated of healthy cells, infected A1 cells, and viral load concentrations in the lymph node and blood compartments under the combined drug and plasma apheresis treatment for a duration of 150 weeks started at week 350 for $\varepsilon=0.5$ (red dashed line), 0.6 (black dotted line) and 0.7 (blue dashed-dot line), compared to the no-treatment situation (black solid line). (a), (b) The numbers of healthy cells in the lymph node and blood compartments, respectively. (c), (d) The numbers of infected A1 cells in the lymph node and blood compartments, respectively. (e), (f) Viral load concentrations in the lymph node and in the lymph node and blood compartments, respectively.

We now hypothesize that if HARRT is prescribed at an appropriately higher dosage during each 5 weeks respite from plasma apheresis treatments than the dosage during each treatment, the high rebounds could be prevented, or at the least dampened enough to guard against possible opportunistic infection in the patient's weaker state immunologically. We proceeded to test this hypothesis by experimenting on our CA model, modified so that the drug potency during plasma apheresis applications, at $T_{a p}=\{250,255,260, \ldots, 400\}$, is given by

$$
P_{d 1}(t)=0.7\left(1+\frac{I_{t}+I_{d 1}}{H_{0}}\right)^{-0.01 \sqrt{\frac{I_{d 1}\left(t-T_{d 1}\right)}{H_{0}}}} \text { if } t \in T_{a p}
$$

where $T_{d 1}=250$, the first time apheresis is applied (at a clearance rate $\varepsilon=0.5$ ).

During the respites from apheresis ( $\varepsilon=0)$, drug combination is prescribed at higher potency (higher $\mu$ ), 
given by

$$
P_{d 2}(t)=0.9\left(1+\frac{I_{t}+I_{d 2}}{H_{0}}\right)^{-0.01} \sqrt{\frac{I_{d 2}}{H_{0}}\left(t-T_{d 2}\right)}
$$

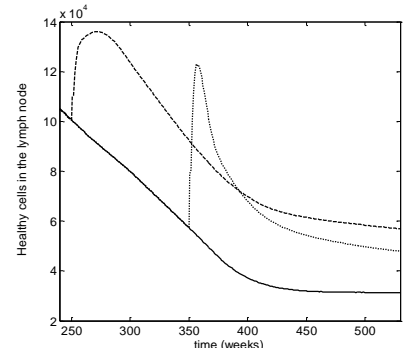

(a)

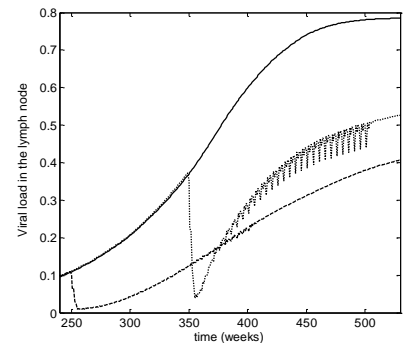

(c)

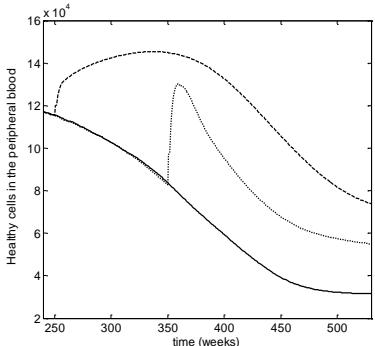

(b)

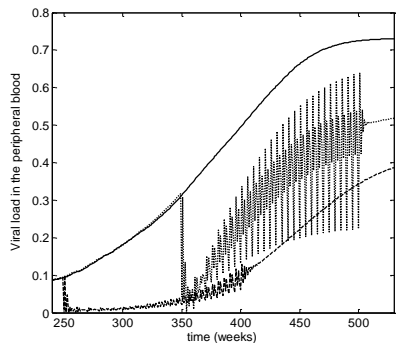

(d)
Fig. 5. Simulated time courses of healthy cells and viral load concentrations in the lymph node and blood compartments under the combined drug and plasma apheresis treatment for a duration of 150 weeks started at week 250 and 350 for $\varepsilon=0.6$. (a), (b) The numbers of healthy cells in the lymph node and blood compartments, respectively. (c), (d) Viral load concentrations in the lymph node and blood compartments, respectively.

If $400 \geq t \geq T_{d 2}$ and $t \notin T_{a p}$, where $T_{d 2}=251$. We also assume that drug resistance should set in more slowly because the patient is not subject to high dosages of drugs for a long period of time, and hence the relatively small coefficient $\eta=$ 0.01 is used in the exponential term.

Once the treatment is abandoned at $t=400$, then the drug potency is given by

$$
P_{d 3}(t)=0.9\left(1+\frac{I_{t}+I_{d 2}}{H_{0}}\right)^{-0.035 \sqrt{\frac{I_{d 2}}{H_{0}}\left(t-T_{d 2}\right)}} \text { if } t \geq 401
$$

in which drug resistance sets in less slowly $(\eta=0.035)$ due to prolonged use of drugs. This alternate treatment with a switch is drug potency is simulated and shown (averaged over 50 runs) in Fig. 6, compared with the simulations of treatment options without potency switch, using

$$
P_{d}(t)=\left\{\begin{array}{l}
0, \quad t<T_{d} \\
\mu\left(1+\frac{I_{t}+I_{d}}{H_{0}}\right)^{-\eta} \sqrt{\frac{I_{d}}{H_{0}}\left(t-T_{d}\right)} \quad, t \geq T_{d}
\end{array}\right.
$$

with $\mu=0.9$, and $\varepsilon=0.5,0.6,0.7$. The drug resistance is assumed to set in more quickly ( $\eta=0.05$ ) due to prolonged use of highly potent drugs without any respites during the apheresis treatments.

We observe in Fig. 6 that, although the normal combined usage of drug and apheresis treatment in these simulations yields markedly better results compared to no treatment at all, the treatment controlled with different drug potency appears to lead to even more favorable eventual outcome, yielding higher healthy cells, and lower viral load in both the lymph node and peripheral blood compartments as time passes.

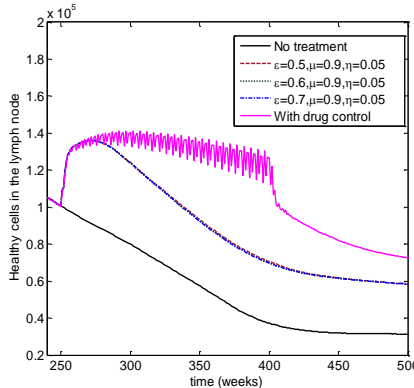

(a)

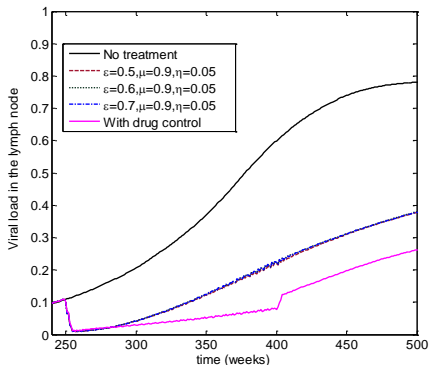

(c)

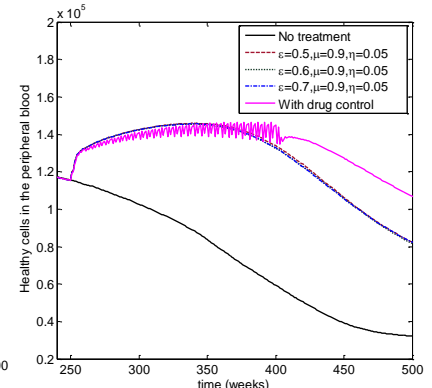

(b)

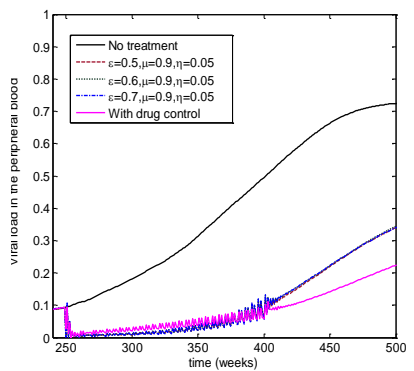

(d)
Fig. 6. Simulated time courses of healthy cells and viral load concentrations in the lymph node and blood compartments under the combined drug and plasma apheresis treatment for a duration of 150 weeks started at week 250 for $\varepsilon=0.5,0.6,0.7, \mu=0.9, \eta=0.05$, compared with the simulated treatment under the control of drug potency (pink curve). (a), (b) The numbers of healthy cells in the lymph node and blood compartments, respectively. (c), (d) Viral load in the lymph node and blood compartments, respectively.

\section{CONCLUSION}

Since aphaeresis has been acceptable treatment for various viral infections such as hepatitis $\mathrm{C}$ infection and cancer [11]-[15], several studies have been carried out to determine whether plasma apheresis may offer a good alternative for the treatment of AIDS patients with peripheral polyneuropathy [16]-[19]. Therefore, before plasma aphaeresis may be recommended as a suitable therapeutic option, giving the patients a better quality of life with some interruptions or rests from drug intakes that are accompanied by serious side effects, it is essential that intensive studies are carried out on the effect of this technique on the dynamics of viral load in both the lymph node and blood compartments as well as the development of the virus-immune response in human.

We propose that stochastic Cellular Automata simulation is the most appropriate technique to investigate the therapeutic outcome of drug prescriptions in combination with interrupted treatment by plasma apheresis, which has been suggested in some reports to be a promising treatment option for patients in the later stages of HIV infection [20]-[26].

Averaged over 50 simulations, the time courses of healthy 
cells, infected A1 cells, and viral load concentrations in the lymph node and blood compartments have been presented and analyzed. Overall, the treatment is capable of reducing the viral load up to half of the level in an untreated patient, if the therapy is provided sufficiently early on in the infection stages. In addition, from considering the trends of these curves as time progresses, we may project that if the combined treatment that starts later is continued longer than 150 weeks, it is possible that its therapeutic effect may be as good as, or no worse than the effect of starting it earlier.

We remark here that our utilization of double latticed CA model can better illustrate the infection dynamics under plasma apheresis, combined with drug therapy, than a model that focuses on the lymph node compartment alone. Considering Fig. 3-6, we clearly see that the impacts of variations in treatment options cannot be at all differentiated by the simulated time courses in the lymph node compartment, but can be clearly observed in the peripheral blood compartment, where the time courses show unmistakable fluctuations.

Moreover, it could be projected from our simulation results that if HARRT is prescribed at an appropriately higher dosage during each 5 weeks respite from plasma apheresis treatments than the dosage during each treatment, the high rebounds could be prevented, or at the least dampened enough to guard against possible opportunistic infection in the patient's weaker state immunologically. Such hypotheses, whereas not practical to be tested on a patient, can be confirmed or contradicted by simulation experiments with our CA model.

Understandably, no data is available in the literatures, to the best of our knowledge, on the time courses of the state variables our model is able to track under apheresis and drug treatments, since such measurements would be very costly and involve ethical considerations. However, several researchers [19]-[22] reported that plasma apheresis in combination with appropriate drug prescription have been in use and appear to have favorable results. Our CA model is thus expected to provide valuable augmentation to current understanding of the impact of such treatment where experimental data may not be readily available.

\section{REFERENCES}

[1] S. R. Hosein. (February 2014). Lymph nodes reveal HIV's hiding place - scientists call for new drugs. CATIE News. [Online]. Available: http://www.catie.ca/en/catienews/2014-02-13/lymph-nodes-reveal-hi $\mathrm{v}$-s-hiding-place-scientists-call-new-drugs

[2] R. M. Z. D. Santos and S. Coutinho, "Dynamics of HIV infection: A cellular automata approach," Physics Review Letters, vol. 87, pp. 168102-168104, Sept. 2001.

[3] A. S. Fauci, G. Pantaleo, S. Stanley, and D. Weissman, "Immunopathogenic mechanisms of HIV infection," Annals of Internal. Medicine, vol. 124, pp. 654-63, Jan. 1996.

[4] L. E. Hood, Immunology, Menlo Park, CA: Benjamin/Cummings Publishing Company, 1984.

[5] C. Kougias and J. Schulte, "Simulating the immune response to the HIV-1 virus with cellular automata," Journal of Statistical Physics, vol. 60, no. 1-2, pp. 263-273, July 1990.

[6] R. Pandey, "Cellular automata approach to interacting cellular network models for the dynamics of cell population in an early HIV infection," Physica A: Statistical Mechanics and Its Applications, vol. 179, pp. 442-470, Dec.1991.

[7] V. Shi, A. Tridane, and Y. Kuang, "A viral load-based cellular automata approach to modeling HIV dynamics and drug treatment," Journal of Theoretical Biology, vol. 253, no. 1, pp. 24-35, July 2008.
[8] S. Moonchai, Y. Lenbury, and W. Triampo, "Cellular automata simulation modeling of HIV infection in Lymph Node and peripheral blood compartments," International Journal of Mathematics and Computers in Simulation, vol. 4, no. 4, pp. 124-134, 2011.

[9] S. Moonchai and Y. Lenbury, "Double compartment ca simulation of drug treatments inhibiting hiv growth and replication at various stages of life cycle," International Journal of Mathematics and Computers in Simulation, vol. 3, no. 3, pp. 232-241, 2011.

[10] S. Moonchai and Y. Lenbury, "Cellular automata simulation of interrupted plasma aphaeresis on AIDS patients: Investigating effects of different clearance rate," International Journal of Mathematics and Computers in Simulation, vol. 7, no. 3, pp. 294-303, 2013.

[11] H. M. Diepolder, N. Kashiwagi, G. Teuber, A. Ulsenheimer, M. Franz, T. Yokoyama, and R. Zachoval, "Leucoytapheresis with Adacolumn (R) enhances HCV-specific proliferative responses in patients infected with hepatitis C virus genotype 1," Journal of Medical Virology, vol. 77, no. 2, pp. 209-215, Oct. 2005.

[12] H. Hasson, A. Saniabadi, M. Alfano, D. Trabattoni, P. Ferrante, F. Lillo, M. Clerici, A. Lazzarin, and A. Beretta, "Granulocyte/monocyte apheresis induces sustained increases in CD4 T cells in HIV-1 infected patients with poor $\mathrm{CD} 4 \mathrm{~T}$ cell restoration after suppression of viral replication by HAART," Journal of Biological Regulators \& Homeostic Agents, vol. 16, no. 1, pp. 58-63, Jan.-Mar. 2002.

[13] K. Sawada, K. Ohnishi, K. Fukunaga, T. Kusaka, M. Ohdo, K. Nagase, T. Shimoyama, and T. Hada, "Granulocyte and monocyte adsorptive apheresis for patients with chronic hepatitis $\mathrm{C}$ virus infection: A report on six cases with high plasma viremia," Therapeutic Apheresis and Dialysis, vol. 7, no. 6, pp. 547-553, Dec. 2003.

[14] T. Yamashita, K. Arai, A. Sakai, E. Mizukoshi, Y. Sakai, T. Kagaya, Y. Nakamoto, M. Honda, T. Wada, and H. Yokoyama, "Virological effects and safety of combined double filtration plasmapheresis (DFPP) and interferon therapy in patients with chronic hepatitis C. A preliminary study," Hepatoogy. Research, vol. 36, no. 3, pp. 167-175, Nov. 2006.

[15] T. Tabuchi, H. Ubukata, A. R. Saniabadi, and T. Soma, "Granulocyte apheresis as a possible new approach in cancer therapy: A pilot study involving two cases," Cancer Detection Prevention, vol. 23, no. 5, pp. 417-421, 1999 .

[16] G. Blick, W. F. Scott, S. W. Crook, S. Buchanan, T. Garton, U. Hopkins, A. M. Vadaboncoeur, J. Doolittle, I. A. Bulcraig, P. Greiger-Zanlungo, and A. Karpas, "Passive immunotherapy in advanced HIV infection and therapeutic plasmapheresis in asymptomatic HIV-positive individuals: A four-year clinical experience," Biotherapy, vol. 1, no. 1, pp. 7-13, 1998.

[17] W. S. Gilmer, "Neurologic problems of the lower extremity associated with HIV and AIDS," Clinics in Podiatric Medicine and Surgery, vol. 15, no. 2, pp. 281-303, Apr. 1998.

[18] T. W. Łapinski and D. Prokopowicz, "The plasmapheresis in patients with AIDS and periphery polyneuropathy accompanies," Polski Tygodnik Lekarski, vol. 7, no. 41, pp. 215-217, Nov. 1999.

[19] B. Ramratnam, S. Bonhoeffer, J. Binley, A. Hurley, L. Zhang, J. E. Mittler, M. Markowitz, J. P. Moore, A. S. Perelson, and D. D. Ho, "Rapid production and clearance of HIV-1 and hepatitis C virus assessed by large volume plasma apheresis," Lancet, vol. 354, no. 9192, pp. 1782-1785, Nov. 1999.

[20] E. J. B. Monteiro, D. Caron, C. A. Balda, M. Franco, A. B. Pereira, and G. M. Kirsztajn, "Anti-glomerular basement membrane glomerulonephritis in an HIV positive patient: case report," Brazilian Journal of Infectious Diseases, vol. 10, 2006.

[21] H. von Baeyer, "Plasmapheresis in immune hematology: review of clinical outcome data with respect to evidence-based medicine and clinical experience," Therapeutic Apheresis and Dialysis, vol. 7, no. 1, pp. 127-140, Feb. 2003.

[22] E. Morales, E. Gutierrez-Solis, E. Gutierrez, and M. Praga, "Glome-rular pathology in patients with HIV infection," in An Update on Glomerulopathies-Clinical and Treatment Aspects, S. S. Prabhakar ed. [Online]. Available: http://medicaltextboks.blogspot.com/2013/05/TEXTBOOK-UPDAT E-GLOMERULOPATHIES-CLINICAL-TREATMENT-ASPECTS.ht $\mathrm{ml}$

[23] S. H. Bajaria, G. Webb, M. Cloyd, and D. Kirschner, "Dynamics of naive and memory CD4+ $\mathrm{T}$ lymphocytes in HIV-1 disease progression," Journal of Acquired Immune Deficiency Syndrome, vol. 30, no. 1, pp. 41-58, May 2002.

[24] P. W. Nelson, J. D. Murray, and A. S. Perelson, "A model of HIV-1 pathogenesis that includes an intracellular delay," Mathematical Biosciences, vol. 163, no. 2, pp. 201-215, Feb. 2000. 
[25] D. J. Steckel, "The role of inter-cellular adhesion in the recirculation of T lymphocytes," Journal of Theoretical Biology, vol. 186, no. 4, pp. 491-501, June 1997.

[26] D. J. Stekel, C. E. Parker, and M. A. Nowak, "A model of lymphocyte recirculation," Immunology Today, vol. 18, pp. 216-221, May 1997.

[27] S. Alizon and C. Magnus, "Modelling the course of an HIV Infection: Insights from ecology and evolution," Viruses, vol. 4, no. 5, pp. 216-221, Oct. 2012.

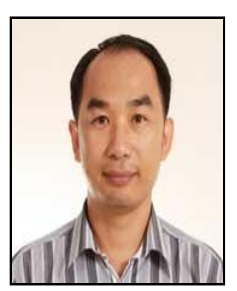

Sompop Moonchai was born in Thailand. $\mathrm{He}$ obtained his Ph.D. degree in mathematics from the Department of Mathematics, Faculty of Science Mahidol University, Bangkok, Thailand.

After graduation, he has been working with the Department of Mathematics, Chiang Mai University in the northern city of Chiang Mai, Thailand. He has published many papers that applied Monte Carlo Cellular Automata Simulation technique to problems in physics or medical science. His current research interest includes simulation and stochastic modeling of infectious diseases.

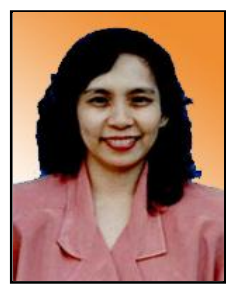

Yongwimon Lenbury was born in Bangkok, Thailand on August 23, 1952. She obtained her Ph.D. degree in mathematics from Vanderbilt University, Nashville, Tennessee, USA, almost 30 years ago.

She has been working at the Department of Mathematics, Faculty of Science, Mahidol University, Bangkok, Thailand, since her graduation. Her research effort has earned her the Outstanding Researcher Award from the National Research Council of Thailand, in the field of physical science and mathematics, and the Thailand Outstanding Scientist Award 2007 from the Foundation for the Promotion of Science and Technology under HM the King's Patronage. Her continued achievements have resulted in her being granted the prestigious position of senior scholar of the Thailand Research Fund in mathematics. She is currently the director of the Centre of Excellence in mathematics, a National Centre under The Ministry of Education. Her research interests include the construction and analysis of mathematical models of systems in biology and medical science, using theory of nonlinear and dynamical systems.

Prof. Yongwimon Lenbury is a member of the Society of Industrial and Applied Mathematics (SIAM), and has recently been elected to be the next president of the East Asia Section of SIAM (EASIAM). She has been a fellow of the Royal Institute of Thailand since 2001. 